\title{
Evaluating Two-Layer Models for Velocity Profiles in Open-Channels with Submerged Vegetation
}

\author{
Xiaonan Tang \\ Department of Civil Engineering, Xi'an Jiaotong-Liverpool University, Suzhou, China \\ Email: xiao.tang@xjtlu.edu.cn
}

How to cite this paper: Tang, X. (2019). Evaluating Two-Layer Models for Velocity Profiles in Open-Channels with Submerged Vegetation. Journal of Geoscience and Environment Protection, 7, 68-80. https://doi.org/10.4236/gep.2019.71006

Received: December 22, 2018

Accepted: January 19, 2019

Published: January 22, 2019

Copyright (อ 2019 by author(s) and Scientific Research Publishing Inc. This work is licensed under the Creative Commons Attribution International License (CC BY 4.0).

http://creativecommons.org/licenses/by/4.0/

\section{cc) (i) Open Access}

\begin{abstract}
For submerged vegetated flow, the velocity profile has two distinctive distributions in the vegetation layer in the lower region and the surface layer in the upper non-vegetated region. Based on a mixing-layer analogy, different analytical models have been proposed for the velocity profile in the two layers. This paper evaluates the four analytical models of Klopstra et al., Defina \& Bixio, Yang et al. and Nepf against a wide range of independent experimental data available in the literature. To test the applicability and robust of the models, the author used the 19 datasets with various relative depths of submergence, different vegetation densities and bed slopes $\left(1.8 \times 10^{-6}-4.0 \times\right.$ $\left.10^{-3}\right)$. This study shows that none of the models can predict the velocity profiles well for all datasets. The three models except Yang's model performed reasonably well in certain cases, but Yang's model failed in most the cases studied. It was also found that the Defina model is almost the same as the Klopstra model, if the same mixing length scale of eddies $(\lambda)$ is used. Finally, close examination of the mixing length scale of eddies $(\lambda)$ in the Defina model showed that when $\lambda / h=1 / 40(H / h)^{1 / 2}$, this model can predict velocity profiles well for all the datasets used.
\end{abstract}

\section{Keywords}

Aquatic Vegetation, Velocity Profile, Vegetated Flow, Analytical Model, Rigid Vegetation, Open-Channel Flow

\section{Introduction}

Vegetation exists in many natural rivers and woodlands. No matter what type the vegetation is, it will alter the velocity field of flow, consequently increasing 
figflow resistance. The influence of vegetation on the velocity of flow depends on its type (rigid or flexible) and condition (submerged or emergent). As a prerequisite for analysis of flow resistance, pollutant mixing process, etc., the velocity profile of vegetated flows has drawn the interest of many researchers. For example, Temple (1986) studied velocity distribution in channels with grass; turbulent structure of vegetated layer was studied (Shimzu \& Tsujimoto, 1994; Nepf \& Koch, 1999; Nepf \& Vivoni, 2000; Lopez \& Garcia, 2001; Dimitris \& Panayotis, 2011). There are extensive studies on the velocity distribution via experimental and analytical methods (Tsujimoto \& Kitamur 1990, Klopstra et al., 1997; Meijer \& Van Velzen, 1999; Nepf \& Koch, 1999; Ghisalberti \& Nepf, 2004; Defina \& Bixio, 2005; Baptist et al., 2007; Kubrak, et al. 2008; Huai et al. 2009; Yang \& Choi, 2010; Nepf, 2012; Tang, 2018).

However, due to different types of vegetation and flow conditions, various methods are proposed for predicting velocity profiles. For the flows with submerged vegetation, the most common method is a two-layer approach, in which different analytical models are applied in the lower vegetation layer and the upper surface layer, using a mixing-layer analogy (Klopstra et al., 1997; Meijer \& Van Velzen, 1999; Defina \& Bixio, 2005; Baptist, et al., 2007; Huai, et al. 2009; Yang \& Choi, 2010; Nepf, 2012; Singh et al. 2019; Tang, 2018). Klopstra et al. (1997) proposed a two-layer model of velocity: one in the vegetation layer and one above it called the surface layer. In the vegetation layer, the turbulent eddy viscosity is expressed by the product of a characteristic length $(\lambda)$ and velocity, following Boussinesq hypothesis. $\lambda$ was found to empirically relate to $H / h$ ( $H$ is the flow depth and $h$ denotes the height of vegetation). After further investigation on this model through more data, Meijer \& Van Velzen (1999) found that $\lambda$ could be approximated by $0.0144 \sqrt{H h}$. Similarly, Defina \& Bixio (2005) established a different form of analytical solution for velocity in the vegetation layer. Yang \& Choi (2010) and Nepf (2012) proposed different empirical models for velocity in the vegetated layer.

Considering only certain data used in the validation of the above-mentioned models, the present study aims at comparing the four models of Klopstra et al. (1997), Defina \& Bixio (2005), Yang \& Choi (2010) and Nepf (2012) for the prediction of velocity profiles in submerged rigid vegetation against a wide range of independent datasets. Thus it is to demonstrate the capability and robust of each model, consequently making some recommendation for the future application. In this study, the 19 datasets used cover different submergence ratios $(\mathrm{H} / \mathrm{h})$ ranging from 1.25 to 3.4 , different vegetation densities (defined as $a$, the frontal area of the vegetation per unit volume) $\left(a=1.1-10 \mathrm{~m}^{-1}\right)$ and bed slopes $S_{o}(1.8 \times$ $\left.10^{-6}-4.0 \times 10^{-3}\right)$.

\section{Description of Models}

In open-channel flow with vegetation, the bed and wall boundary stress are both negligible compared with the drag force on the vegetation (Nepf \& Vivoni, 2000; Stone \& Shen, 2002). Thus, the momentum equation of steady fully-developed 
1-D vegetated flow may be described as (Klopstra et al., 1997; Ghisalberti \& Nepf, 2004; Defina \& Bixio, 2005; Kubrak et al., 2008; Tang, 2018):

$$
\frac{\partial \tau(z)}{\partial z}=F_{v}-g S_{o}
$$

where $\tau$ is the shear stress, $g$ the gravity, $z$ the vertical coordinate above the bed, $S_{o}$ the bed slope and $F_{V}$ is the drag force per unit mass generated by the vegetation, see Figure 1 . The drag force $F_{V}$ is given by:

$$
F_{v}=\left\{\begin{array}{ll}
\frac{1}{2} C_{D} a u^{2}, & z \leq h \\
0, & z>h
\end{array} ; a=m A_{v}\right.
$$

where $h$ is the height of vegetation, $\mathrm{u}$ the local stream wise velocity, $C_{D}$ the drag coefficient, $a$ the frontal area of vegetation $\left(A_{v}\right)$ per unit volume, representing the density of vegetation, and $m$ is the number of vegetation per unit area.

Using Boussinesq's hypothesis on eddy viscosity combined with a mixing-length concept (Defina \& Bixio, 2005; Baptist et al. 2007), the Reynolds stress $(\tau)$ is described as:

$$
\tau(z)=\rho v_{T} \frac{\partial u}{\partial z}=\rho \lambda u \frac{\partial u}{\partial z}
$$

where $v_{\mathrm{T}}$ is the total eddy viscosity of vegetated flow, and $\lambda$ is a mixing length.

Under steady flow condition, inserting Equations (2) \& (3) into (1) gives:

$$
\lambda \frac{\partial^{2}\left(u^{2}\right)}{\partial z^{2}}-C_{D} a u^{2}+2 g S_{o}=0
$$

For given $a$ and $C_{D}$, one can obtain an analytical solution for $u^{2}$ in Equation (4) under appropriate boundary conditions (e.g. Klopstra et al., 1997; Defina \& Bixio, 2005). The boundary conditions are as follows:

$$
u_{o}=\left.u\right|_{z=0}=\sqrt{\frac{2 g S_{o}}{a C_{D}}}
$$

At the bed $(z=0)$, where the bed shear stress is neglected compared with drag force of vegetation, the local equilibrium between vegetation drag and gravity force leads to:

$$
\left.\tau\right|_{z=h}=\rho g(H-h) S_{o}
$$

At the top of the vegetation $(z=h)$, the Reynolds stress is described as:

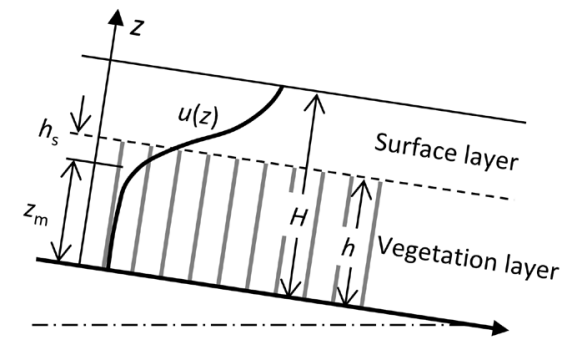

Figure 1. Velocity profile in a channel with submerged vegetation. 


\subsection{Model by Klopstra et al. (1997)}

For the vegetation layer, Equation (4) has the following analytical solution for the velocity under boundary conditions (5) \& (6):

$$
u_{z}=\sqrt{C_{1} \mathrm{e}^{-\sqrt{2 A} z}-C_{1} \mathrm{e}^{\sqrt{2 A} z}+u_{0}^{2}}
$$

in which,

$$
\begin{gathered}
C_{1}=\frac{-2 g S_{o}(H-h)}{\lambda \sqrt{2 A}\left(\mathrm{e}^{h \sqrt{2 A}}+\mathrm{e}^{-h \sqrt{2 A}}\right)} \\
A=\frac{a C_{D}}{2 \lambda} \\
\lambda=0.0793 h \ln \left(\frac{H}{h}\right)-0.0009 \quad \text { when } \lambda \geq 0.001
\end{gathered}
$$

For the surface layer, the velocity is described by the well-known logarithmic profile:

$$
u=\frac{u_{*}}{\kappa} \ln \left(\frac{z-z_{m}}{z_{o}}\right)=\frac{u_{*}}{\kappa} \ln \left[\frac{z-\left(h-h_{s}\right)}{z_{o}}\right]
$$

where $\kappa$ is von Karman's constant $(0.40), z_{m}\left(=h-h_{s}\right)$ is the zero-plane displacement of the logarithmic profile, $h_{s}$ is the distance between the top of vegetation and the virtual bed of the surface layer (see Figure 1), $z_{o}$ is the equivalent height of bed roughness, and $u_{*}$ is the shear velocity, given by:

$$
\begin{gathered}
u_{*}=\sqrt{g S_{o}(H-h)} \\
h_{s}=g \frac{1+\sqrt{1+\frac{4 E^{2} \kappa^{2}(H-h)}{g}}}{2 E^{2} \kappa^{2}} \\
z_{o}=h_{s} \mathrm{e}^{-F}
\end{gathered}
$$

where

$$
\begin{gathered}
E=\frac{-C_{1} \sqrt{2 A / S_{o}} \mathrm{e}^{h \sqrt{2 A}}}{2 \sqrt{u_{0}^{2}-C_{1} \mathrm{e}^{h \sqrt{2 A}}}} \\
F=\frac{\kappa \sqrt{u_{0}^{2}-C_{1} \mathrm{e}^{h \sqrt{2 A}}}}{\sqrt{g S_{o}\left[H-\left(h-h_{s}\right)\right]}}
\end{gathered}
$$

\subsection{Model by Defina and Bixio (2005)}

Based on Equation (4) with similar assumptions, and using the mixing length concept, Defina \& Bixio (2005) proposed another form of velocity profile by introducing a parameter $\beta$, which depends on $\lambda / h$. The velocity profile is described as follows:

For the vegetation layer: 


$$
u=\sqrt{\frac{2 g S_{o}}{\beta\left(\lambda / h^{2}\right)}\left\{\left(\frac{H}{h}-1\right) \frac{\sinh \left[\beta\left(\frac{z}{h}\right)\right]}{\cosh (\beta)}+\frac{1}{\beta}\right\}} ; \beta=\sqrt{\frac{C_{D} a h}{\lambda / h}}
$$

where $\lambda$ is recommended to be $0.0144 \sqrt{H h}$.

For the surface layer, the velocity is described by the same Equation (11), where $h_{s}$ and $z_{o}$ are respectively given by:

$$
\begin{gathered}
h_{s}=\frac{g S_{o}+\sqrt{\left(g S_{o}\right)^{2}+4\left(\kappa \partial u /\left.\partial z\right|_{z=h}\right)^{2} g S_{o}(H-h)}}{2\left(\kappa \partial u /\left.\partial z\right|_{z=h}\right)^{2}} \\
z_{o}=h_{s} \mathrm{e}^{-\kappa\left(\frac{\left.u\right|_{z=h}}{u_{*}}\right)}
\end{gathered}
$$

\subsection{Model by Yang and Choi (2010)}

Yang and Choi (2010) proposed a two-layer model that predicts the velocity profile for flows with both flexible and rigid submerged vegetation. The flow through the vegetation is assumed to be driven by gravity and the shear force generated at the top of the vegetation. This is a result of the co-flowing between the low speed vegetation layer and relatively higher speed surface layer, together with the drag force of vegetation. Thus, the flow velocity in the vegetation layer is given by:

$$
u_{1}=\sqrt{\frac{2 g H S_{o}}{C_{D} a h}}
$$

The flow in the upper non-vegetated layer is assumed to be driven by gravity force and Reynolds stresses, leading to a logarithmic profile as:

$$
\frac{u}{u_{1}}=\frac{c_{u} u_{*}}{\kappa} \ln \left(\frac{z}{h}\right)+1
$$

where $c_{u}$ is recommended as 2 when $a>5$; otherwise it is 1 .

\subsection{Model by Nepf (2012)}

Nepf (2012) proposed a model using an empirical equation to describe the velocity profile in the vegetation layer. Although the model is supposed to be applicable to both flexible and rigid vegetation, most of its parameters are only proposed for rigid vegetation. Therefore, only the parameters for the rigid vegetation are introduced here. For the surface layer, the velocity profile is assumed as Equation (11), where $z_{m}$ and $z_{0}$ are given by:

$$
\begin{gathered}
z_{m}=h-\frac{0.1}{a C_{D}} \\
z_{0}=(0.04 \pm 0.02) a^{-1}
\end{gathered}
$$

where $z_{0}$ is recommended for $a h>0.1$; otherwise, $z_{0}$ is estimated as $0.1 h$ (Nepf \& Ghisalberti, 2008). 
The vegetation layer is divided into two zones, which depends on the penetration of the turbulence stresses from the surface layer into the vegetation layer. An empirical Equation (24) is proposed for estimating the depth of turbulent shear penetration $(\delta)$ for $(a h)$ values of $(0.2-3)$ :

$$
\delta=\frac{0.23 \pm 0.6}{a C_{D}}
$$

Therefore in the upper zone of the vegetation layer $(h-\delta<Z<h)$, the flow is driven by gravity and turbulent stresses and balanced by vegetation drag. The velocity profile is assumed to be exponential:

$$
\begin{gathered}
u=u_{2}+\left(u_{h}-u_{2}\right) \exp \left[-k_{u}(h-z)\right] \\
k_{u}=(8.7 \pm 1.4) a C_{D}
\end{gathered}
$$

where $u_{h}=u$ at the top of the vegetation, and $u_{2}=$ velocity in the lower region of vegetation $(z<h-\delta)$, which is described by Equation (5).

\section{Data for Study}

To compare the four models in Section 2, we used a wide range of different ex-

\begin{tabular}{|c|c|c|c|c|c|c|c|}
\hline Authors & Run & $\begin{array}{l}\text { Flow depth } \\
\text { (m) }\end{array}$ & $H / h$ & $\begin{array}{c}\text { Frontal area } \\
a\left(\mathrm{~m}^{-1}\right)\end{array}$ & $\mathrm{C}_{\mathrm{D}}$ & $\mathrm{S}_{\mathrm{o}}$ & $\mathrm{a} h$ \\
\hline \multirow{2}{*}{ Dunn et al. (1996) } & 8 & 0.391 & 3.33 & 2.46 & 1.13 & 0.0036 & 0.289 \\
\hline & 9 & 0.214 & 1.82 & 2.46 & 1.13 & 0.0036 & 0.289 \\
\hline \multirow{5}{*}{$\begin{array}{l}\text { Ghisalberti \& Nepf } \\
\qquad(2004)\end{array}$} & B & 0.467 & 3.36 & 2.5 & 1.4 & 0.0000018 & 0.348 \\
\hline & $\mathrm{C}$ & 0.467 & 3.36 & 3.4 & 1.1 & 0.000025 & 0.473 \\
\hline & G & 0.467 & 3.38 & 4 & 1.1 & 0.000013 & 0.552 \\
\hline & $\mathrm{H}$ & 0.467 & 3.38 & 8 & 0.79 & 0.0001 & 1.104 \\
\hline & $\mathrm{J}$ & 0.467 & 3.38 & 8 & 0.92 & 0.000013 & 1.104 \\
\hline \multirow{2}{*}{$\begin{array}{l}\text { Huai et al. } \\
\qquad(2009)\end{array}$} & 1 & 0.291 & 1.53 & 1.2 & 1 & 0.0004 & 0.228 \\
\hline & 2 & 0.383 & 2.02 & 1.2 & 1 & 0.0004 & 0.228 \\
\hline \multirow{2}{*}{$\begin{array}{l}\text { Lopez \& Garcia } \\
\qquad(2001)\end{array}$} & 01 & 0.335 & 2.79 & 1.09 & 1.13 & 0.0036 & 0.131 \\
\hline & 09 & 0.214 & 1.78 & 2.49 & 1.13 & 0.0036 & 0.299 \\
\hline \multirow{3}{*}{$\begin{array}{c}\text { Meijer \& Van Velzen } \\
\qquad(1999)\end{array}$} & 22 & 2.08 & 2.31 & 2.048 & 0.97 & 0.00138 & 1.843 \\
\hline & 34 & 0.99 & 2.20 & 2.048 & 0.97 & 0.0016 & 0.922 \\
\hline & 36 & 1.50 & 3.33 & 2.048 & 0.97 & 0.0014 & 0.922 \\
\hline Nepf \& Vivoni (2000) & 7 & 0.44 & 2.75 & 4.14 & 1.4 & 0.0002 & 0.662 \\
\hline \multirow{2}{*}{$\begin{array}{l}\text { Shimizu \& Tsujimoto } \\
\qquad(1994)\end{array}$} & A31 & 0.0936 & 2.03 & 3.75 & 1.0 & 0.0026 & 0.173 \\
\hline & R32 & 0.0747 & 1.82 & 10 & 1.0 & 0.00213 & 0.410 \\
\hline \multirow[t]{2}{*}{ Hao et al. (2014) } & Test 1 & 0.10 & 1.25 & 1.355 & 1.13 & 0.0035 & 0.108 \\
\hline & Test 2 & 0.11 & 1.38 & 1.355 & 1.13 & 0.004 & 0.108 \\
\hline
\end{tabular}
perimental data from the literature for submerged rigid vegetation. Table 1

Table 1. The dataset used for evaluating the models of submerged rigid vegetation. 
summarizes a total of 19 datasets used in this study. These datasets include different submergence ratio, i.e. $H / h=1.25$ - 3.4, various vegetation densities $a=$ $1.1-10 \mathrm{~m}^{-1}$ and bed slopes $S_{o}$ between $1.8 \times 10^{-6}$ and $4.0 \times 10^{-3}$. Note that the data of Dunn et al. (1996) and runs 34 and 36 of Meijer \& Van Velzen (1999) are extracted from Dimitris \& Panayotis (2011). The values of $C_{D}$ in the dataset of emergent vegetation were estimated for all runs, taken from the original papers.

\section{Results}

For simplicity of analysis, the models by Klopstra et al. (1997), Defina \& Bixio (2005), Yang \& Choi (2010) and Nepf (2012) are denoted as Klopstra, Defina, Yang and Nepf models respectively in the subsequent sections.

\subsection{Comparison of Results between the Models}

The comparisons between the four models are shown in Figures 2-4, which demonstrate that all the models, except the Yang model, can predict profiles reasonably well for the lower zone of vegetation. However, none of them can predict the velocity profile well in the surface layer for all the data tested. For the
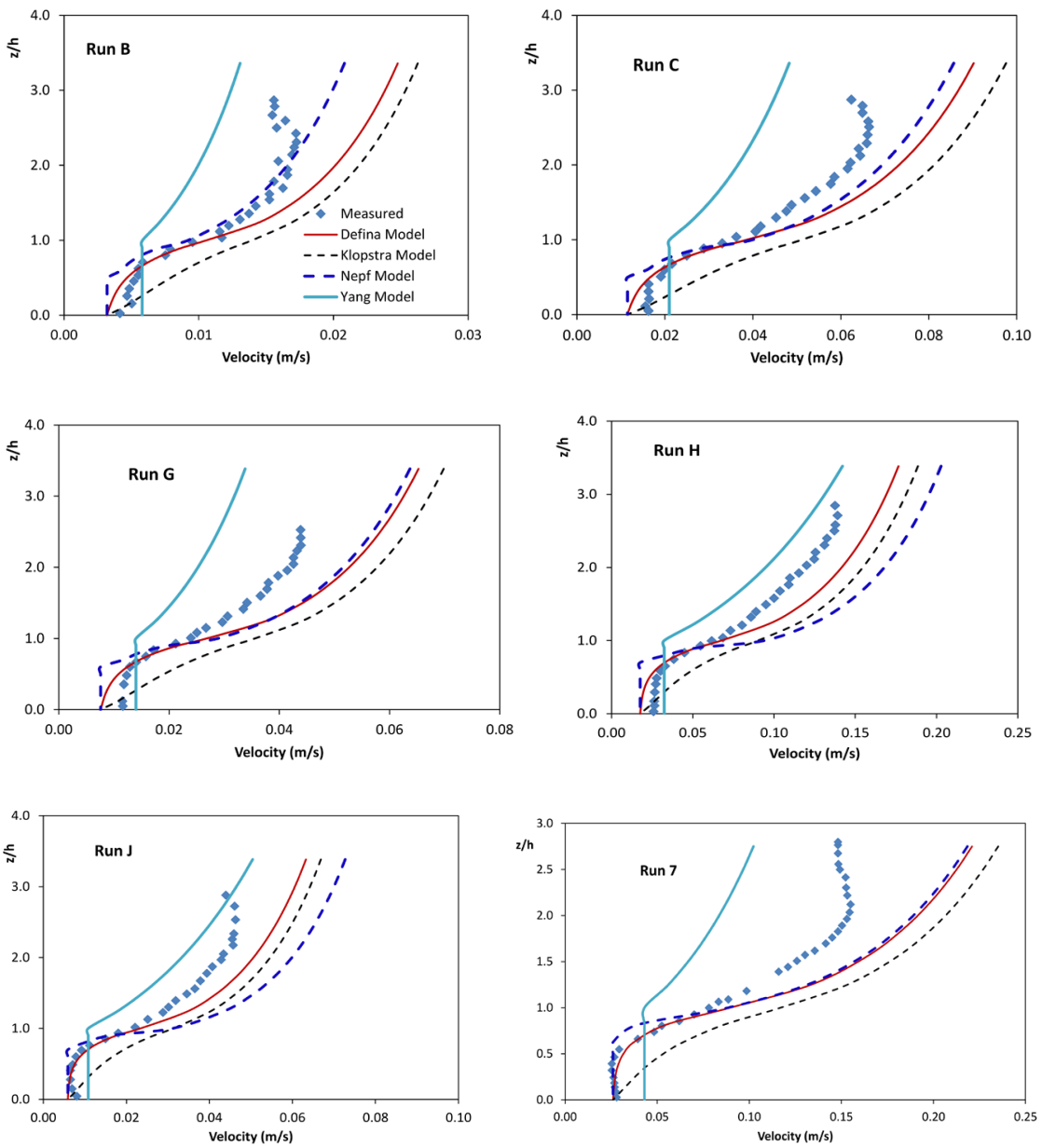

Figure 2. Comparison for the experimental data: Ghisalberti \& Nepf (2004): B, C, G, H, J and Nepf \& Vivoni (2000): 7. 

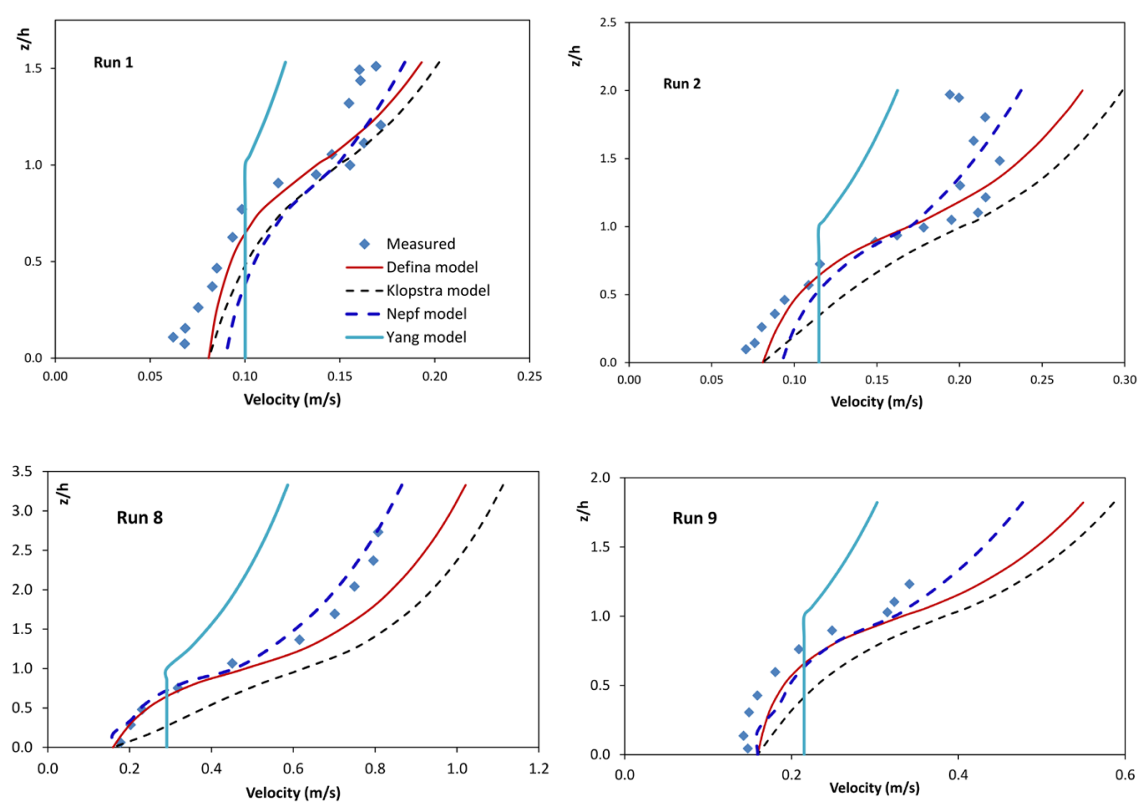

Figure 3. Comparison for the experimental data: Huai et al. (2009): 1 \& 2; Dunn et al. (1996): 8 \& 9 .
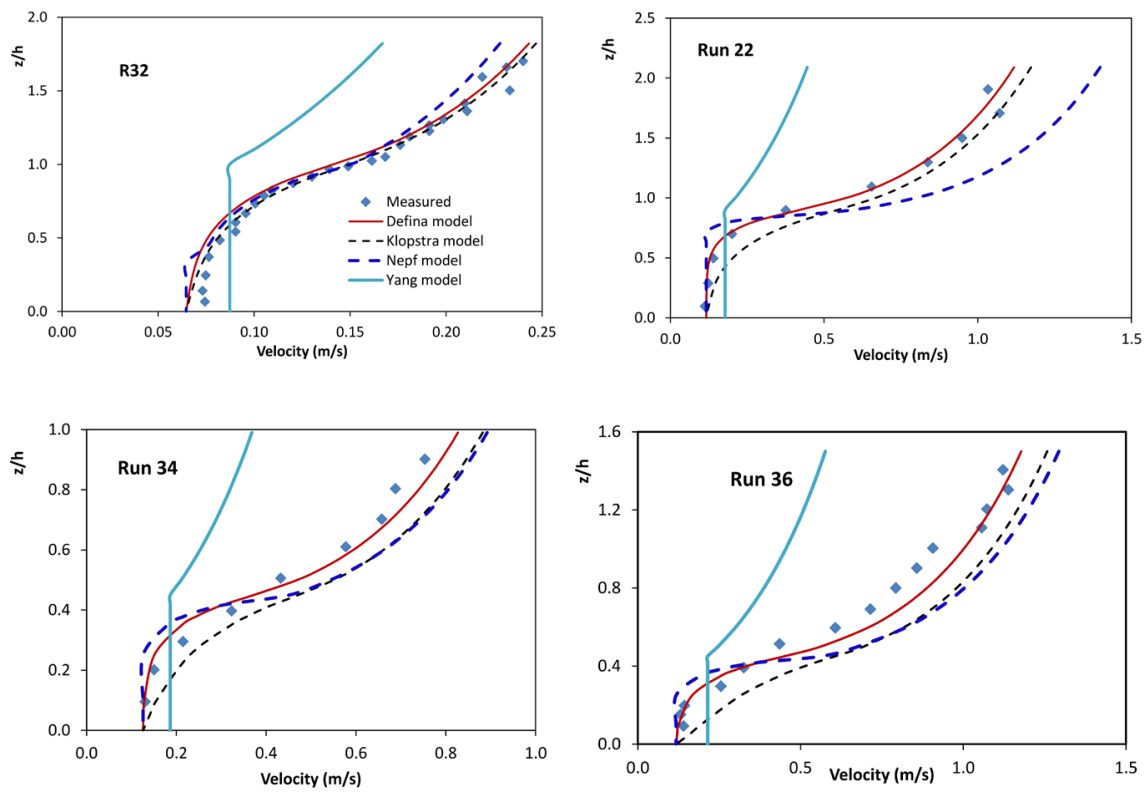

Figure 4. Comparison for the experimental data: Meijer \& Van Velzen (1999): 22, 34 \& 36; Shimizu \& Tsujimoto (1994): R32.

surface layer, both Klopstra and Yang models under-estimate, particularly the Yang model significantly under-estimates the prediction for all the data, whereas the Defina and Nepf models both over-estimate the velocity in most cases although the two models can predict reasonably well in certain cases. For example, the Defina model predicts reasonably well for the data by Huai et al. (2009), Meijer \& Van Velzen (1999), and Shimizu \& Tsujimoto (1994), whilst the Nepf model does well for the data by Dunn et al. (1996), Huai et al. (2009) and Shi- 
mizu \& Tsujimoto (1994) in Figure 3 and Figure 4. It is not surprising that the Defina model predicts well for the data of Meijer \& Van Velzen (1999) as the same value of $\lambda$ was used in the Defina model. It appears that both models performs reasonably well when $H / h$ is not very large (e.g. $H / h<2.0$ ).

Despite the Klopstra and Defina models having similar assumptions, the Defina model performs better than the Klopstra model in most cases. The reason appears from the different $\lambda$ models used. Close examination shows that if the same $\lambda$ model is used, the predicted velocity profiles are almost the same although $z_{0}$ and $z_{m}$ proposed by the two models are different. Note that the Klopstra model did not consider the effect of the 1st term on the right side of Equation (18).

The Nepf model does not perform well in some cases. This is mainly due to the insufficiency of the formulas of velocity profile in the vegetation layer. The proposed formula for calculating the velocity in the upper zone of vegetation depends on two velocity predictions: one $\left(u_{2}\right)$ at the top of vegetation and the other $\left(u_{o}\right)$ in the lower part of the vegetation. Therefore, if these two velocities deviate from the measured ones significantly then the formula for the upper zone of vegetation will underperform. The proposed formula for the lower zone of vegetation neglects the dispersive, turbulent and viscous stresses and, as mentioned before, in the above experiments the vegetation is deeply penetrated by the turbulent stress and in such cases the dispersive stress might become significant. Bearing in mind that this model is based on the empirical equations for estimation of $z_{m}$ and $z_{o}$, which is dependent on $\mathrm{C}_{\mathrm{D}}$ and vegetation density (a), further study is needed about the empirical Equations (22) \& (23).

The predicted velocity by the Yang model significantly deviates from the measured ones. It can be argued that assuming a uniform distribution of velocity profile over the whole vegetation depth is not a realistic assumption. The measured velocity profile in the vegetation in most of the cases tested herein is exponential for a large part of the vegetation depth. Moreover, in some cases illustrated here, this model has predicted the velocity very close to the measured one but the trend is not well captured because the assumption of a uniform velocity does not reflect reality. The inaccuracy of the logarithmic part might be explained from the following two aspects. First, the equation for the surface layer depends on the predicted velocity in the vegetation layer. Therefore, the accuracy of the model in the surface layer is partly dependent on the precision of prediction in the vegetation layer. Second, examining the measured data indicates that the penetration of turbulent stresses into the vegetation layer is significant, so the effective roughness should be much smaller than the vegetation height, which is taken as the effective roughness in this model. Therefore, in all cases the velocity in the upper region is under-estimated.

\subsection{Further Discussion on Klopstra \& Defina Models}

Further examination of the Defina and Klopstra models shows that their differences are very small if the same $\lambda$ value is used. Because both $z_{0}$ and $h_{s}$ are im- 
portant to describe the velocity in the surface layer, they relate to the $\lambda$ value in the models. Since both flow depth and vegetation height will have impact on $\lambda$ (characteristic length of eddy), $\lambda$ may be represented by $\lambda=k \sqrt{H h}$, where $k$ is a constant. The predicted velocity by both models decreases as increasing $\mathrm{k}$ value, because the larger the $k$ value, the bigger $\lambda$ becomes, i.e. the stronger the eddy, indicating a smaller velocity. Close studies on all the data tested suggest that when $k=1 / 40$ both models have good agreement with the data, as shown in Figures 5-8.

\section{Conclusion}

In a river with submerged vegetation, the velocity profile in the lower vegetation layer is significantly different from the upper non-vegetation surface layer. Comparison has been made on four commonly used two-layer models of velocity profile: Klopstra et al. (1997), Defina \& Bixio (2005), Yang \& Choi (2010) and Nepf (2012). This study has demonstrated that all the models except the Yang model can predict the velocity reasonably well in the vegetation layer near the bed. However, in the surface layer none of the models using their default parameter
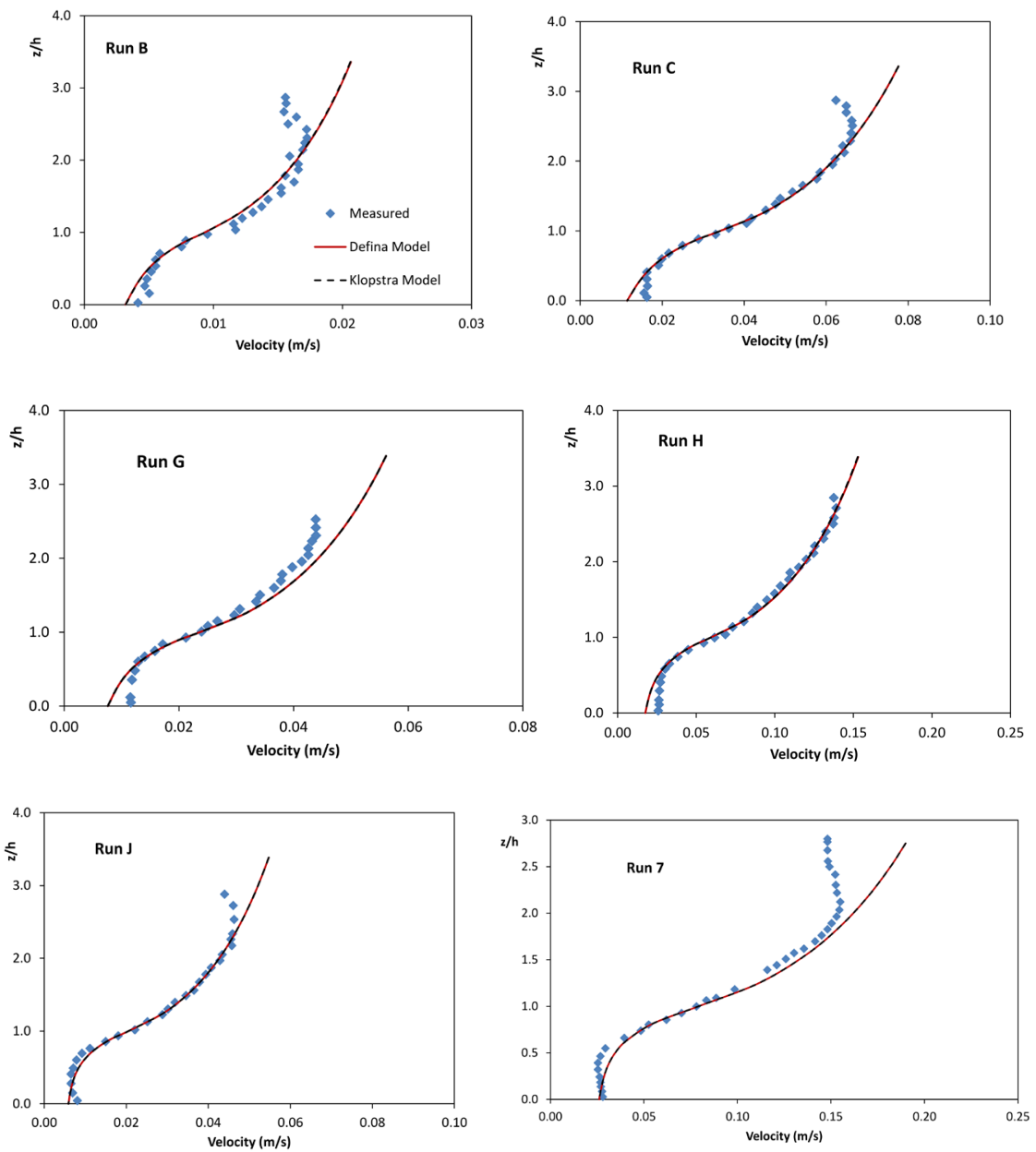

Figure 5. Comparison for the experimental data: Ghisalberti \& Nepf (2004): B, C, G, H, J and Nepf \& Vivoni (2000): 7. 

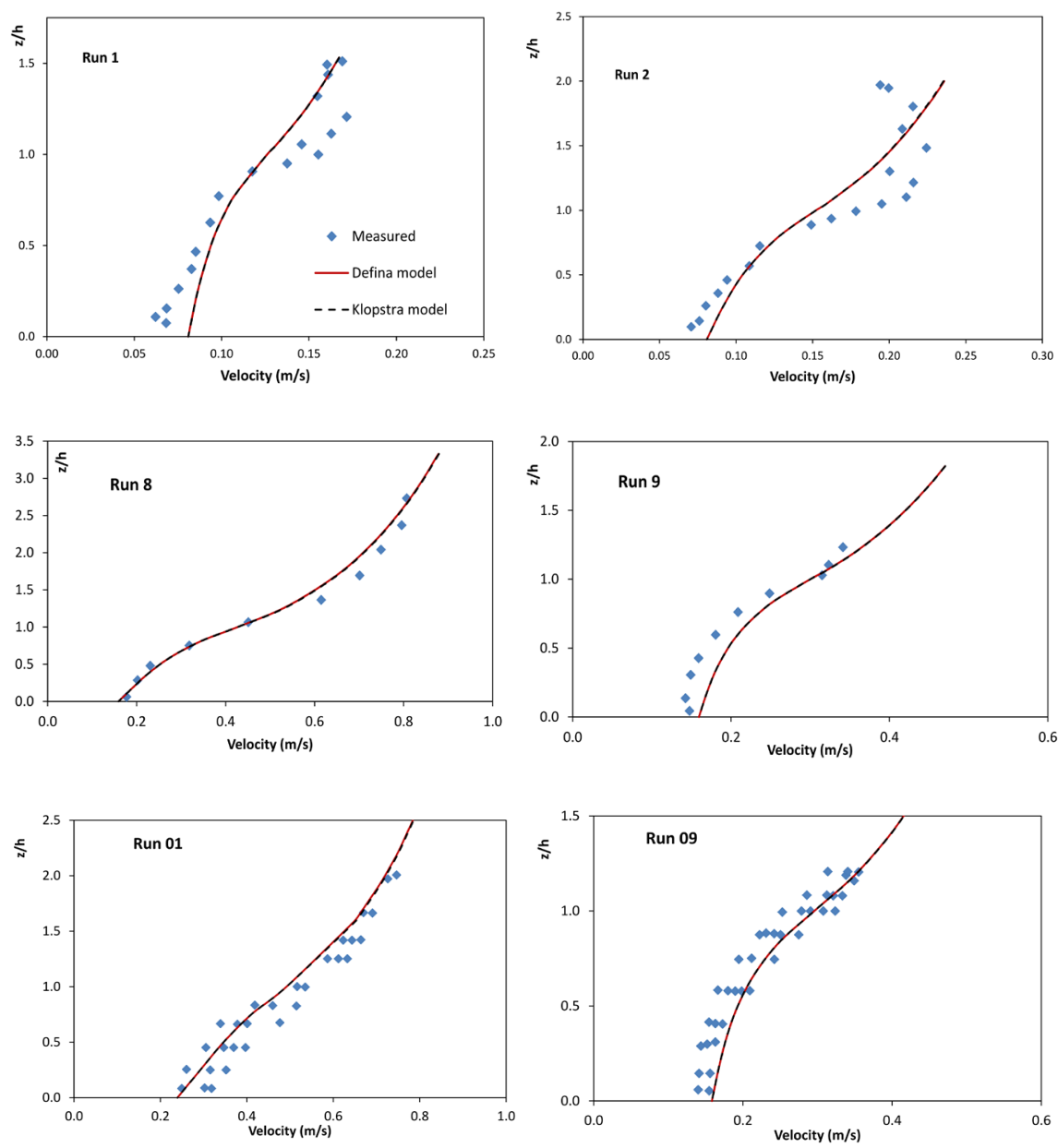

Figure 6. Comparison for the experimental data: Dunn et al. (1996): 8 \& 9; Huai et al. (2009): 1 \& 2; Lopez \& Garcia (2001): 01 \& 09.
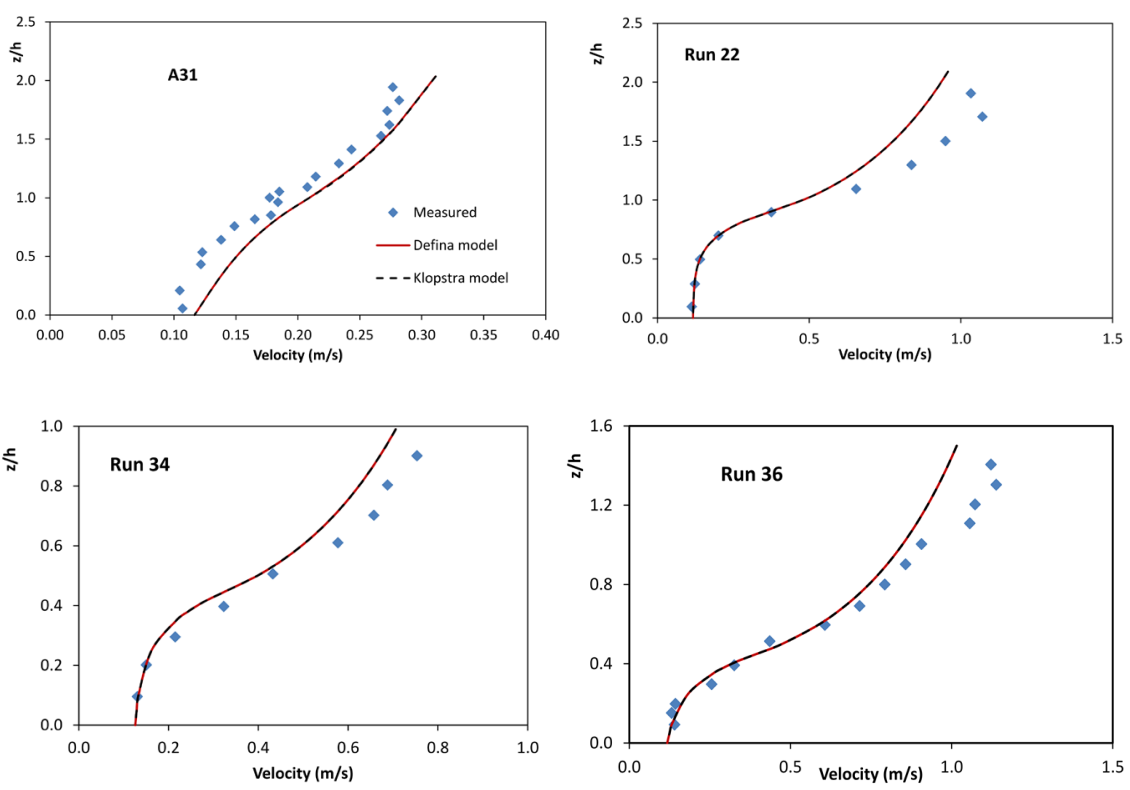

Figure 7. Comparison for the experimental data: Meijer \& Van Velzen (1999): 22, 34 \& 36; Shimizu \& Tsujimoto (1994): A31. 

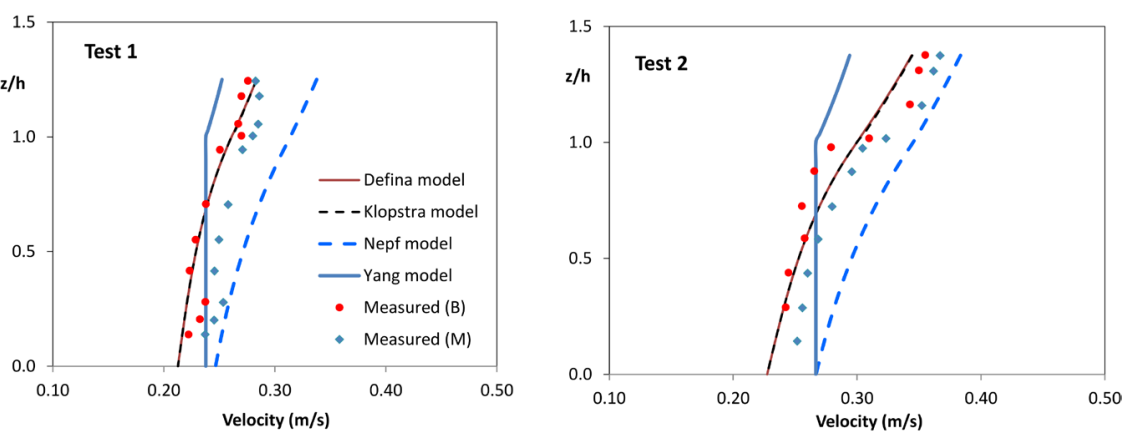

Figure 8. Comparison for the experimental data of Hao et al. (2014).

values can predict velocities well for a wide range of vegetation $(H / h=1.25$ 3.4). Both the Klopstra and Yang models significantly under-estimate the velocity. The Nepf model can predict reasonably well for certain cases with lower density of vegetation, i.e. $a h$ is up to 0.35 . However, the Defina model is more capable of prediction for a relatively large range of cases.

Close examination of $\lambda$ parameters in the Defina and Klopstra models shows that the two models are very close when the same parameter $\lambda$ value is used. This study shows that when $\lambda$ is described by $k \sqrt{H h}$ with $k$ having an optimum value of $1 / 40$, the Defina and Klopstra models can both predict the velocity profiles well for a wide range of vegetated flows. More data are needed for examining the new recommended value of $k$ in future research.

\section{Acknowledgements}

The author would like to acknowledge the financial support by the National Natural Science Foundation of China (11772270) and the Research Development Funding of XJTLU (RDF-15-01-10).

\section{Conflicts of Interest}

The author declares no conflicts of interest regarding the publication of this paper.

\section{References}

Baptist, M. J., Babovic, V., Rodriguez Uthubrubu, J., Keijzer, M., Uittenbogaadr, R. E., Mynett, A., \& Verwey, A. (2007). On Inducing Equations for Vegetation Resistance. Journal of Hydraulic Research, 45, 435-450. https://doi.org/10.1080/00221686.2007.9521778

Defina, A., \& Bixio, A. C. (2005). Mean Flow and Turbulence in Vegetated Open Channel Flow. Water Resources Research, 41, W07006. https://doi.org/10.1029/2004WR003475

Dimitris, S., \& Panayotis, P. (2011). Macroscopic Turbulence Models and Their Application in Turbulent Vegetated Flows. Journal of Hydraulic Engineering, 137, 315-332. https://doi.org/10.1061/(ASCE)HY.1943-7900.0000307

Ghisalberti, M., \& Nepf, M. H. (2004). The Limited Growth of Vegetated Shear Layers. Water Resources Research, 40, w07502. https://doi.org/10.1029/2003WR002776

Hao, W. L., Zhu, C. J., \& Chang, X. P. (2014). Research on Vertical Distribution of Longitudinal Velocity in the Flow with Submerged Vegetation. Journal of Heibei 
University of Engineering, 31, 64-67. (In Chinese)

Huai, W. X., Chen, Z., \& Han, J. (2009). Mathematical Model for the Flow with Submerged and Emerged Rigid Vegetation. Journal of Hydrodynamics, 21, 722-729. https://doi.org/10.1016/S1001-6058(08)60205-X

Klopstra, D., Barneveld, H. J., Noortwijk, J. M., \& Velzen, E. H. (1997). Analytical Model for Hydraulic Roughness of Submerged Vegetation. Theme A. Proceedings of 27th IAHR Congress, San Francisco: ASCE, 775-780.

Kubrak, E., Kubrak, J., \& Rowinski, P. M. (2008). Vertical Velocity Distribution through and above Submerged, Flexible Vegetation. Hydrological Sciences Journal, 53, 905-920. https://doi.org/10.1623/hysj.53.4.905

Lopez, F., \& Garcia, M. H. (2001). Mean Flow and Turbulence Structure of Open-Channel Flow through Non-Emergent Vegetation. Journal of Hydraulic Engineering, 127, 392-402. https://doi.org/10.1061/(ASCE)0733-9429(2001)127:5(392)

Meijer, D. G., \& Van Velzen, E. H. (1999). Prototype-Scale Flume Experiments on Hydraulic Roughness of Submerged Vegetation. 28th International IAHR Conference, Graz, Austria.

Nepf, H. M. (2012). Flow and Transport in Regions with Aquatic Vegetation. Annual Reviews Fluid Mechanics, 44, 123-142. https://doi.org/10.1146/annurev-fluid-120710-101048

Nepf, H. M., \& Ghisalberti, M. (2008). Flow and Transport in Channels with Submerged Vegetation. Acta Geophysica, 56, 753-777. https://doi.org/10.2478/s11600-008-0017-y

Nepf, H. M., \& Vivoni, E. R. (2000). Flow Structure in Depth-Limited, Vegetated Flow. Journal of Geophysical Research, 105, 28547-28557. https://doi.org/10.1029/2000JC900145

Nepf, H., \& Koch, E. W. (1999). Vertical Secondary Flows in Submerged Plant-Like Arrays. Limnology and Oceanography, 44, 1072-1080.

https://doi.org/10.4319/lo.1999.44.4.1072

Shimizu, Y., \& Tsujimoto, T. (1994). Numerical Analysis of Turbulent Open-Channel Flow over a Vegetation Layer Using k-Turbulence Model. Journal of Hydroscience and Hydraulic Engineering, 11, 57-67.

Singh, P., Rahimi, H., \& Tang, X. (2019). Parameterization of the Modeling Variables in Velocity Analytical Solutions of Open-Channel Flows with Double-Layered Vegetation. Environmental Fluid Mechanics. https://doi.org/10.1007/s10652-018-09656-8

Stone, B. M., \& Shen, H. T. (2002). Hydraulic Resistance of Flow in Channels with Cylindrical Roughness. Journal of Hydraulic Engineering, 128, 500-506. https://doi.org/10.1061/(ASCE)0733-9429(2002)128:5(500)

Tang, X. (2018). A Mixing-Length-Scale-Based Analytical Model for Predicting Velocity Profiles of Open Channel Flows with Submerged Rigid Vegetation. Water and Environment Journal, 32, 1-10. https://doi.org/10.1111/wej.12434

Temple, D. M. (1986). Velocity Distribution Coefficients for Grass-Lined Channels. Journal of Hydraulic Engineering, 112, 193-205. https://doi.org/10.1061/(ASCE)0733-9429(1986)112:3(193)

Tsujimoto, T., \& Kitamur, T. (1990). Velocity Profile of Flow in Vegetated Bed Channels (pp. 43-55). KHL Progress Report 1, Hydrualic Lab., Kazavava University.

Yang, W., \& Choi, S. (2010). A Two-Layer Approach for Depth-Limited Open Channel Flows with Submerged Vegetation. Journal of Hydraulic Research, 48, 466-475. https://doi.org/10.1080/00221686.2010.491649 